\title{
Nalokson nesespray kan redusere risikoen for dødelige heroinoverdoser
}

\author{
Philipp Paul Koren Lobmaier ${ }^{1,2}$, Therese Kristine Dalsbø ${ }^{3}$ og Thomas Clausen ${ }^{1}$ \\ 1) Senter for Rus- og Avhengighetsforskning (SERAF), Universitetet i Oslo \\ 2) Senter for Rus- og Avhengighetsbehandling, Klinikk A, Oslo Universitetssykehus HF \\ 3) Nasjonalt kunnskapssenter for helsetjenesten \\ Korrespondanse: Philipp Lobmaier, SERAF, Kirkeveien 166, bygg 45, 0450 Oslo \\ E-post: p.p.lobmaier@medisin.uio.no Telefon: 23368954 Telefaks: 23368986
}

\begin{abstract}
SAMMENDRAG
Bakgrunn: Antall overdosedødsfall blant heroinmisbrukere i Norge er høyt. Behandling med motgiften nalokson er kun tilgjengelig gjennom helsepersonell. Nalokson kan også gis som nesespray av ikke helsepersonell. Økt tilgjengelighet av nalokson kan redusere både antall fatale overdoser og fare for stikkskader og blodsmitte med hepatitt $\mathrm{C}$ og hiv blant helsepersonell. I denne artikkelen presenterer vi kunnskap om bruk av nalokson nesespray $\mathrm{i}$ behandling av opioidoverdoser.

Material og metode: Vi har gjennomført søk etter relevant forskning om effekt av nalokson nesespray i databasene Medline, Embase og Cochrane library. Artikler er valgt ut basert på skjønn og forhåndsbestemte kriterier om behandling og pasientpopulasjon. Det var ingen restriksjoner på hvilken studiedesign som var benyttet eller metodologisk kvalitet. Konklusjonen er basert på innhentet material.

Resultater: Ni relevante studier ble identifisert og inkludert, hvorav fire hadde kontrollgrupper men kun to var randomiserte sammenligninger. Ingen av studiene var utført i Norge. Nalokson nesespray gitt grunnet mistanke om opioidoverdose synes å føre til rask klinisk respons. Ved sammenligning med dagens praksis med injisert nalokson peker funn mot nesten like rask normalisering av åndedrett ved nesespray. Bruk av nalokson nesespray kan gi redusert behov for nalokson injeksjoner og derfor redusert fare for stikkskade blant helsepersonell. Hvis også legfolk utenom helsepersonell læres opp til å gi nalokson nesespray vil tilgjengeligheten av motgift og kunnskap rundt forebygging av overdoser kunne økes.

Fortolkning: Det er foreløpig for få studier av høy kvalitet til å kunne konkludere endelig med effekt av nesespray. Men de studiene som foreligger tyder på at nalokson i form av nesespray kan være effektiv i behandlingen av overdoser. Nalokson nesespray anbefales derfor utprøved ytterligere i randomiserte studier i Norge sammenlignet med dagens praksis. Videre bør opplæringen i bruk for pårørende, brukere og ansatte i eksisterende lavterskeltiltak evalueres da dette vil kunne øke nalokson tilgjengeligheten og bidra til å redusere antallet overdosedødsfall.
\end{abstract}

\section{Lobmaier PPK, Dalsbø TK, Clausen T. Nasal naloxone may reduce the risk of death from heroin overdose. Nor J Epidemiol 2011; 21 (1): 107-111.}

\section{ENGLISH SUMMARY}

Background: The number of overdose deaths among heroin users in Norway is high. Treatment with the opioid antidote naloxone is available only through trained health care staff. Naloxone can also be administered as nasal spray by non-health care staff. Increasing naloxone availability may reduce both the number of overdose deaths, the risk of needlestick injuries and the transmission of blood-borne viruses such as Hepatitis C and HIV. This paper reviews the use of nasal naloxone for the treatment of opioid overdose.

Material and method: We have conducted a scoping search for relevant literature on the effects of naloxone nasal spray in the electronic databases Medline, Embase and The Cochrane Library. The reports that were judged relevant based on our expertise and on predefined criteria were included in the review. No restrictions were made regarding study design or methodological quality. Conclusions are based on data from the included studies.

Results: Four of the nine studies included had control groups, but only two were randomised. No study was conducted in Norway. Nasal naloxone appeared to quickly result in clinical improvement when treating overdoses that are presumably caused by opioids. Comparing injectable naloxone (as the usual route of administration) with nasal administration, the results indicate almost equally fast respiratory normalization with nasal spray. Use of naloxone nasal spray can reduce the need to inject naloxone and therefore reduces the risk of needlestick injuries among health care staff. Training of non-health care laypersons in the use of naloxone nasal spray has the potential to increase naloxone availability and knowledge about overdose events.

Conclusion: We did not find enough evidence to unequivocally support the effectiveness of naloxone nasal spray. Despite the scarce evidence, naloxone nasal spray appears promising in the treatment of overdoses and it should therefore be compared with standard care in a randomised controlled trial in Norway. Training in administration for heroin users and staff at low threshold facilities should be evaluated as better availability of naloxone nasal spray can potentially reduce overdose deaths. 


\section{INNLEDNING}

En alvorlig følge av heroinbruk er faren for akutt opioidforgiftning. En slik forgiftning omtales vanligvis som overdose og kan blant annet medføre bevisstløshet, koma, respirasjonsstans og hjertestans med døden til følge. Ulike tilleggsfaktorer kan øke risikoen for dødelige overdoser; samtidig bruk av andre beroligende eller dempende midler som alkohol og benzodiazepiner eller nedsatt toleranse for opioider, som etter gjennomført avgiftning.

Injeksjon av nalokson i vene eller muskel har vist seg effektiv i å forhindre dødelig utgang av opioid forgiftning. Nalokson er en korttidsvirkende, spesifikk opioid reseptor antagonist med høy affinitet for $\mu$ opioid reseptorer. Peroralt nalokson har ingen virkning på grunn av førstepassasjeeffekt $\mathrm{i}$ leveren som begrenser biotilgjengeligheten til mindre enn 1\% (1). Vanligvis gis nalokson intravenøst eller intramuskulært og virketiden er omtrent 3 til 4 timer (halveringstid på 70 minutter). Nalokson fortrenger opioid-agonister ved opioid reseptorene og reverserer effektivt opioid forgiftning inklusive respirasjonsstans, sedasjon og lavt blodtrykk (2).

Ved mistanke om opioid forgiftning gis normalt opp til $2 \mathrm{mg}$ nalokson intravenøst og den kliniske responsen forventes å inntre i løpet av få minutter. Dersom responsen uteblir kan nalokson dosen gjentas med 0,4 til $2 \mathrm{mg}$ inntil effekt (3). Dersom respons uteblir etter til sammen $10 \mathrm{mg}$ nalokson er en opioid forgiftning usannsynlig. Halveringstiden av nalokson er kort, derfor anbefales intramuskulær dose $(0,4 \mathrm{mg})$ nalokson i tillegg til intravenøst for å oppnå tilstrekkelig effekt over tid. Nalokson i sprøyte til muskulær injisering har vist seg å gi sammenlignbar effekt som intravenøs administrering (4).

Nalokson gitt til friske frivillige vil ha lite klinisk effekt og innebærer liten fare for bivirkninger (5). Hos heroinpåvirkede vil nalokson imidlertid utløse en abstinensreaksjon, inklusive stoffsug. Nalokson bør derfor ideelt gis som en serie mindre doser og tilpasses ønsket klinisk effekt som er økt oppmerksomhet og forbedret pustefrekvens. Abstinensreaksjonen kan være sterkt ubehagelig og kan blant annet ledsages av forvirring, selv om abstinensen vanligvis ikke er dødelig (6).

Nalokson har så langt $i$ all hovedsak blitt administrert i sprøyteform av helsepersonell. Akuttsituasjoner kan fremstå lite egnet for optimal medisinsk overdosebehandling (bevisstløse personer funnet på trange steder med dårlige lysforhold) og hos sprøytebrukere kan det være svært vanskelig å finne en egnet vene for injisering av motgift. Bruk av sprøyter i slike situasjoner innebærer også en viss risiko for stikkskader og smitte med hepatitt $\mathrm{C}$ og hiv for helsepersonellet. Nalokson i en annen administrasjonsform enn sprøyte har derfor vært etterspurt og nalokson nesespray har blitt forsøkt med lovende resultater, og med betydelig akuttmedisinsk potensial $(7,8)$. Begrensningen i nesespray ligger i mengde væske som kan absorberes gjennom nese- slimhinnen. Gis mer enn $1 \mathrm{ml}$ væske per nesebor vil det renne ut igjen. Dessuten vil neseblod (epistaxis) eller andre mekaniske hindringer (for eksempel etter hodetraumer) kunne vanskeliggjøre bruk av nesespray. Nalokson i $1 \mathrm{mg}$ doser kan blandes ut i 1 eller $0,5 \mathrm{ml}$ væske og ulike forstøvere for nasal administrasjon er kommersielt tilgjengelig og relativt rimelig $(<80$ NOK) (9).

I Norge er det anslagsvis 10000 sprøytemisbrukere og de fleste av disse injiserer opioider, mens et mindretall nok primært injiserer amfetamin (10). Heroinavhengige som ikke er i behandling har økt risiko for å dø med en mortalitetsrate på opp til $4 \%$ per år og overdoser utgjør viktigste årsak. Injeksjon av heroin er en risikofaktor for heroinoverdoser sammenlignet med røyking som administrasjonsform: ved heroinrøyking er opptak til blod (og hjernen) langsommere enn ved injeksjon og overdose vil derfor være mindre sannsynlig.

Norge er på Europatoppen når det gjelder forekomst av dødelige overdoser, men med omkring 400 narkotikarelaterte dødsfall i årene 2000 og 2001 er nå tallet redusert til omtrent 250 per år (10). Anslagsvis $2 / 3$ av disse dødsfallene ansees å være opioidrelaterte og behovet for å intensivere arbeidet med å forhindre overdosedødsfall er påpekt nylig (11). Blant de nesten 3000 årlige overdosene i Oslo i tidsrommet 2003/04 (dødelige og ikke-dødelige) dominerte opioider og spesielt heroin som årsak (12). Det ble også slått fast at nesten halvparten av de overdoseutsatte pasientene i Oslo fikk motgiften nalokson som en del av behandlingen.

På grunn av den høye forekomsten av overdoser i Norge er det av spesiell interesse å undersøke hva slags alternativer til injeksjon av nalokson som finnes, og om andre grupper enn helsepersonell kan læres opp til å iverksette denne livreddende behandlingen. Nasal administrasjon av nalokson har blitt foreslått. Kan for eksempel brukerne selv, deres pårørende, personale på væresteder for rusmisbrukere, politiet eller andre læres opp til å gi førstehjelp med nalokson?

Formålet med denne artikkelen er å beskrive kunnskapen om nalokson nesespray $i$ behandling av overdoser, spesielt sammenlignet med nalokson i sprøyteform. Vi beskriver også evalueringen av nalokson nesespray gitt gjennom brukere og ansatte ved lavterskeltiltak.

\section{Materiale Og Metode}

Grunnlaget for artikkelen er et litteratursøk i databasene Embase og Medline og i databasene til The Cochrane Collaboration utført i desember 2010 og oppdatert i juni 2011. Vi valgte ut 9 artikler blant 38 treff etter en skjønnsmessig vurdering basert på vår erfaring innen avhengighetsmedisin og kunnskapsoppsummering, og ut fra forhåndsbestemte kriterier om at artiklene måtte handle om nesespray og nalokson. Vi ekskluderte ikke artikler på bakgrunn av språk, metode eller metodologisk kvalitet. Artiklene ble innhentet, referanselister ble sjekket og supplert med artikler som vi hadde kjennskap til fra før. 
Tabell 1. Studier på intranasal sammenlignet med injisert nalokson.

\begin{tabular}{|c|c|c|c|}
\hline Studie & Populasjon & Intervensjon; studiedesign & Hovedfunn \\
\hline $\begin{array}{l}\text { Robertson } 2009 \\
\text { (Fresno, USA) }\end{array}$ & $\begin{array}{l}154 \text { personer med } \\
\text { mistanke om } \\
\text { opioid overdose }\end{array}$ & $\begin{array}{l}\text { Nalokson nesespray sammenlignet med } \\
\text { intravenøs; retrospektiv journal } \\
\text { gjennomgang }\end{array}$ & $\begin{array}{l}\text { Like rask klinisk respons i begge gruppene } \\
\text { målt fra kontakttid, raskere respons målt fra } \\
\text { i.v. dosering enn spray, mer behov for ekstra } \\
\text { nalokson i nesespraygruppen ( } 34 \text { vs } 18 \% \text { ) }\end{array}$ \\
\hline $\begin{array}{l}\text { Kelly } 2005 \\
\text { (Melbourne, } \\
\text { Australia) }\end{array}$ & $\begin{array}{l}155 \text { bevisstløse } \\
\text { personer med } \\
\text { mistanke om } \\
\text { opioid overdose }\end{array}$ & $\begin{array}{l}2 \mathrm{mg} \text { nalokson gitt enten intranasalt (5 } \\
\text { ml) eller intramuskulært av ambulanse- } \\
\text { personell, mer i.m. nalokson ved behov; } \\
\text { randomisert sammenligning }\end{array}$ & $\begin{array}{l}\text { Raskere respons i i.m. enn i.n. gruppen: } 6 \text { vs. } \\
8 \text { minutter; også noe mer abstinens } \\
\text { (agitasjon) i i.m. gruppen ( } 13 \text { vs. } 2 \%) \text {. Kun } \\
\text { trend mot større behov for ekstra i.m. } \\
\text { nalokson i nesespraygruppe. }\end{array}$ \\
\hline $\begin{array}{l}\text { Kerr } 2009 \\
\text { (Melbourne, } \\
\text { Australia) }\end{array}$ & $\begin{array}{l}172 \text { bevisstløse } \\
\text { personer med } \\
\text { mistanke om } \\
\text { opioid overdose }\end{array}$ & $\begin{array}{l}2 \text { mg nalokson gitt enten intranasalt ( } 1 \\
\text { ml) eller intramuskulært av ambulanse- } \\
\text { personell, mer i.m. nalokson ved behov; } \\
\text { randomisert sammenligning }\end{array}$ & $\begin{array}{l}\text { Like raskt respons i begge gruppene, mer } \\
\text { behov for ekstra nalokson (i.m.) i } \\
\text { nesespraygruppen ( } 18 \text { vs. } 5 \% \text { ) }\end{array}$ \\
\hline $\begin{array}{l}\text { Merlin } 2010 \\
\text { (New Jersey, } \\
\text { USA) }\end{array}$ & $\begin{array}{l}93 \text { personer med } \\
\text { opioid overdose }\end{array}$ & $\begin{array}{l}1 \mathrm{mg} \text { nalokson per nesebor } \\
\text { sammenlignet med intravenøs nalokson } \\
(0,4 \text { til } 2 \mathrm{mg}) \text {; retrospektiv journal } \\
\text { gjennomgang }\end{array}$ & $\begin{array}{l}\text { Like raskt klinisk respons i begge gruppene, } \\
\text { mer behov for ekstra nalokson } \mathrm{i} \\
\text { nesespraygruppen ( } 42 \text { vs } 20 \%)\end{array}$ \\
\hline
\end{tabular}

\section{ReSUltater}

\section{Studier på nalokson nesespray}

To av de ni studiene som undersøkte effekt av nalokson nesespray var prospektive kohortstudier uten sammenligningsgruppe $(13,14)$, to var evalueringer av nalokson som et lavterskeltiltak $(15,16)$, én var en liten pilotstudie (17), to var retrospektive journalgjennomganger $(18,19)$ og to var randomisert-kontrollerte studier $(20,21)$. Tabell 1 gir en oversikt over de fire sistnevnte studier med kontrollgruppe, Tabell 2 oppsummerer de resterende fem studier på nalokson nesespray uten kontrollgruppe.

Fra en retrospektiv gjennomgang av 154 pasientjournaler i California er det rapportert at nalokson nesespray virker noe langsommere enn sprøyte (19). Tid fra pasientkontakt til klinisk effekt var imidlertid ikke forskjellig med ca. 20 minutter til naloksonvirkning i begge gruppene. Dette funnet ble bekreftet i en annen retrospektiv sammenligning, men her hadde flere i nesespray gruppen behov for ekstra nalokson (18).

Resultatene av en australsk randomisert studie (RCT) peker i samme retning (21). I denne prospektive sammenligningen ble 172 personer med pustestopp og mistanke om overdose tilfeldig fordelt til behandling med nalokson enten injisert muskulært eller som nesespray. Behandlingen ble utført av ambulansepersonell utenfor sykehus. Sjansen for å få normalisert åndedrett innen ti minutter var tilnærmet lik $\mathrm{i}$ de to gruppene med $72,3 \%$ for de som fikk nesespray mot $77,5 \%$ for gruppen med muskulært injisert nalokson. En tidligere RCT, også gjennomført i Melbourne av den samme arbeidsgruppen viste en noe raskere effekt av injisert nalokson sammenlignet med nesespray, muligens fordi $5 \mathrm{ml}$ nesespray inneholdt nalokson med for lav konsentrasjon (20).

I to amerikanske prospektive kohortstudier ble det konkludert med at for de av deltakerne som faktisk responderte på nalokson var det svært mange som fikk tilstrekkelig effekt etter bare å ha fått nalokson i form av nesespray. I et fåtall av tilfellene måtte også intravenøs nalokson gis for å oppnå nødvendig behandlingseffekt. For de som fikk positiv effekt av nalokson via nesespray kom responsen gjennomsnittlig innen 3,4 minutter og konklusjon var at nesespray bør være innledende behandling ved mistanke om opioidoverdose $(13,14)$. Se Tabell 2 for flere funn fra studier uten kontrollgruppe.

\section{Administrasjon av nalokson fra ambulansepersonale og legfolk}

Nalokson nesespray har blitt forsøkt som første tiltak, før ambulansepersonell injiserer nalokson. I en oversiktsartikkel trekker Kerr og medforfattere frem at å gi nalokson nesespray vil gjøre arbeidet for ambulansepersonell tryggere ved at det reduserer risikoen for stikkskader med mulig infisert blod (22). Nalokson nesespray er i økende grad populært av flere grunner: også legfolk med ikke-medisinsk bakgrunn som er vitner til overdoser vil kunne gi livreddende behandling dersom nesespray er tilgjengelig (23). Opplæring i bruken av nalokson nesespray som førstehjelp trenger ikke å ta mer enn 20 til 60 minutter. Instruksjonen kan med fordel inkludere filmsnutter som støtte og praktisk trening i hjerte-lunge-redning; også godtgjørelse for deltagelse i slik opplæring vil øke interessen blant brukerne (24). I tidsskrift for den norske legeforening nylig bekreftet Dale at nesespray er så enkelt å administrere at i gitte situasjoner vil det være aktuelt også for legfolk (7). Kelly trekker frem potensialet for at miljøarbeidere med litt opplæring i bruken av naloksonnesespray også vil kunne redde liv (17). For pasienter har vi grunn til å tro at nesespray vil oppleves som en enklere behandlingsform, og det har nylig blitt hevdet at å forenkle tilgangen til nalokson nesespray vil ytterligere forbedre skadereduksjonstiltak og forebygging av dødelige overdoser (25).

Denne oversiktsartikkelen har viktige begrensinger. 
Tabell 2. Intranasal nalokson som førstehjelpstiltak, studier uten kontrollgruppe.

\begin{tabular}{|c|c|c|c|}
\hline Studie & Populasjon & Intervensjon & Hovedfunn \\
\hline $\begin{array}{l}\text { Barton 2002* } \\
\text { (Denver, USA) }\end{array}$ & $\begin{array}{l}30 \text { bevisstløse personer } \\
\text { utenfor sykehus }\end{array}$ & $\begin{array}{l}1 \mathrm{mg} \text { nalokson per nesebor fulgt av } \\
\text { standard i.v. nalokson ved behov; } \\
\text { pilotstudie }\end{array}$ & $\begin{array}{l}11 \text { personer responderte på nalokson, } \\
\text { derav } 10 \text { på spray uten behov for sprøyte }\end{array}$ \\
\hline $\begin{array}{l}\text { Barton } 2005 \\
\text { (Denver, USA) }\end{array}$ & $\begin{array}{l}95 \text { bevisstløse personer } \\
\text { utenfor sykehus }\end{array}$ & $\begin{array}{l}\text { Samme opplegg som Barton 2002; } \\
\text { større materiale enn pilotstudie }\end{array}$ & $\begin{array}{l}52 \text { responderte på nalokson, derav } 43 \text { på } \\
\text { spray uten behov for sprøyte }\end{array}$ \\
\hline $\begin{array}{l}\text { Doe-Simkins } \\
2009 \text { (Boston, } \\
\text { USA) }\end{array}$ & $\begin{array}{l}385 \text { brukere fikk } \\
\text { opplæring om OD og } \\
\text { utlevert nalokson } \\
\text { nesespray }\end{array}$ & $1 \mathrm{mg}$ nalokson per nesebor inntil x 2 & $\begin{array}{l}50 \text { brukere hadde anvendt nalokson } \\
\text { nesespray } 74 \text { ganger, alle vellykket og } \\
21 \text { derav med ekstra støtte fra } \\
\text { ambulansepersonalet }\end{array}$ \\
\hline $\begin{array}{l}\text { Kelly } 2002 \\
\text { (Melbourne, } \\
\text { Australia) }\end{array}$ & $\begin{array}{l}6 \text { pasienter med } \\
\text { heroinoverdose } \mathrm{i} \\
\text { akuttmottak }\end{array}$ & $\begin{array}{l}0,8 \text { til } 2 \mathrm{mg} \text { nalokson nesespray; } \\
\text { case serie }\end{array}$ & Alle 6 responderte på maks 2 minutter \\
\hline $\begin{array}{l}\text { Kerr } 2008 \\
\text { (Melbourne, } \\
\text { Australia) }\end{array}$ & $\begin{array}{l}99 \text { brukere av } \\
\text { sprøyterom }\end{array}$ & $\begin{array}{l}\text { Kartlegging av synspunkter om } \\
\text { nalokson anvendbarhet }\end{array}$ & $\begin{array}{l}89 \% \text { mente at økt bruker tilgang til } \\
\text { nalokson er god idé; } 74 \% \text { foretrakk } \\
\text { nesespray grunnet redusert smittefare }\end{array}$ \\
\hline
\end{tabular}

* Data inngår trolig som en del av det senere publiserte materialet i Barton 2005.

For det første gjennomførte vi ikke et uttømmende litteratursøk og det er derfor noe usikkert om vårt målrettede søk fant alle relevante studier. For det andre fant vi kun to randomiserte studier, altså forskningsdesignet som ansees å være avgjørende for å bedømme effekten av et tiltak med mest mulig presisjon. Om legfolk opplært i bruk av nalokson nesespray effektivt kan bidra til redusert overdose dødelighet forblir derfor ubesvart da det ikke er rapportert annet enn observasjonsstudier på etablering av slike tiltak. Til tross for disse begrensningene virker nalokson nesespray lovende nok og kan med fordel evalueres som nytt tiltak for å redusere antall overdoser i Norge.

\section{KONKLUSJON}

Vi fant få studier publisert de senere årene som rapporterer at nalokson nesespray reverserer opioid overdoser effektivt. Selv om studiene per i dag ikke kan gi endelig svar på om effekten av nesespray eller injisert nalokson er like god, ser det ut som at nalokson nesespray har en rekke fordeler fremfor injeksjon: nesespray reduserer faren for blodsmitte fra stikkskader og spray kan etter opplæring gis av flere enn ambulansepersonell som f.eks. brukerne selv, andre nærstående personer som familie eller behandlere. Antallet sprøytemisbrukere som dør av opioidoverdose i Norge hvert år er høy og derfor anbefales randomiserte forsøk for å evaluere nalokson nesespray. Også utprøving med nalokson nesespray som nytt skadereduserende og livreddende tiltak bør kunne settes i gang. For å øke fokus på forebygging av overdoser bør nalokson nesespray gjøres tilgjengelig gjennom opplæring av pårørende, brukere og ansatte i både lavterskeltiltak (sprøyterom, hybelhus) og i mer spesialisert helsetjeneste (rusakuttmottak, legevakt, legemiddelassistert rehabilitering). Økt tilgjengelighet av nalokson nesespray $\mathrm{i}$ brukernære miljøer har potensial til å redusere antall overdosedødsfall ved at flere personer nær de heroinavhengige vil kunne bidra i innsatsen for redusert overdosedødelighet i Norge.

\section{REFERANSER}

1. Berkowitz BA. The relationship of pharmacokinetics to pharmacological activity: morphine, methadone and naloxone. Clin Pharmacokinet 1976; 1: 219-30.

2. Handal KA, Schauben JL, Salamone FR. Naloxone. Ann Emerg Med 1983; 12: 438-45.

3. Sporer KA. Acute heroin overdose. Ann Intern Med 1999; 130: 584-90.

4. Sporer KA, Firestone J, Isaacs SM. Out-of-hospital treatment of opioid overdoses in an urban setting. Acad Emerg Med 1996; 3: 660-7.

5. Loimer N, Hofmann P, Chaudhry HR. Nasal administration of naloxone for detection of opiate dependence. $J$ Psychiatr Res 1992; 26: 39-43.

6. Osterwalder JJ. Naloxone - for intoxications with intravenous heroin and heroin mixtures - harmless or hazardous? A prospective clinical study. J Toxicol Clin Toxicol 1996; 34: 409-16.

7. Dale O. [Your nose - not only for blowing!]. Tidsskr Nor Laegeforen 2010; 130: 1326.

8. Ashton H, Hassan Z. Best evidence topic report. Intranasal naloxone in suspected opioid overdose. Emerg Med J 2006; 23: 221-3. 
9. Wolfe TR, Bernstone T. Intranasal drug delivery: an alternative to intravenous administration in selected emergency cases. J Emerg Nurs 2004; 30: 141-7.

10. SIRUS. The Drug Situation in Norway 2009. Oslo: Norwegian Institute for Alcohol and Drug Research, 2009.

11. Clausen T, Havnes IA, Waal H. [Overdose statistics - a complicated account]. Tidsskr Nor Laegeforen 2009; 129: 2233-6.

12. Heyerdahl F, Hovda KE, Bjornaas MA, et al. Pre-hospital treatment of acute poisonings in Oslo. BMC Emerg Med 2008; 8: 15.

13. Barton ED, Ramos J, Colwell C, et al. Intranasal administration of naloxone by paramedics. Prehosp Emerg Care 2002; 6: 54-8.

14. Barton ED, Colwell CB, Wolfe T, et al. Efficacy of intranasal naloxone as a needleless alternative for treatment of opioid overdose in the prehospital setting. J Emerg Med 2005; 29: 265-71.

15. Doe-Simkins M, Walley AY, Epstein A, et al. Saved by the nose: Bystander-administered intranasal naloxone hydrochloride for opioid overdose. Am J Public Health 2009; 99: 788-91.

16. Kerr D, Dietze P, Kelly A-M, et al. Attitudes of Australian heroin users to peer distribution of naloxone for heroin overdose: Perspectives on intranasal administration. J Urban Health 2008; 85: 352-60.

17. Kelly AM, Koutsogiannis Z. Intranasal naloxone for life threatening opioid toxicity. Emerg Med J 2002; 19: 375.

18. Merlin MA, Saybolt M, Kapitanyan R, et al. Intranasal naloxone delivery is an alternative to intravenous naloxone for opioid overdoses. Am J Emerg Med 2010; 28: 296-303.

19. Robertson TM, Hendey GW, Stroh G, et al. Intranasal naloxone is a viable alternative to intravenous naloxone for prehospital narcotic overdose. Prehosp Emerg Care 2009; 13: 512-5.

20. Kelly A-M, Kerr D, Dietze P, et al. Randomised trial of intranasal versus intramuscular naloxone in prehospital treatment for suspected opioid overdose. Med J Aust 2005; 182: 24-7.

21. Kerr D, Kelly AM, Dietze P, et al. Randomized controlled trial comparing the effectiveness and safety of intranasal and intramuscular naloxone for the treatment of suspected heroin overdose. Addiction 2009; 104: 2067-74

22. Kerr D, Dietze P, Kelly A-M. Intranasal naloxone for the treatment of suspected heroin overdose. Addiction 2008; 103: 379-86.

23. Costantino HR, Illum L, Brandt G, et al. Intranasal delivery: Physicochemical and therapeutic aspects. Int $J$ Pharm 2007; 337: 1-24.

24. Green TC, Heimer R, Grau LE. Distinguishing signs of opioid overdose and indication for naloxone: an evaluation of six overdose training and naloxone distribution programs in the United States. Addiction 2008; 103: $979-89$.

25. Wermeling DP. Opioid harm reduction strategies: focus on expanded access to intranasal naloxone. Pharmacotherapy 2010; 30: 627-31. 